\title{
Pengaruh Metode Pembelajaran Bermain Dan Drill Terhadap Hasil Belajar Keterampilan Heading Bolavoli Gandu Level II Pada Siswa SMP
}

\author{
Andy Tri Dianto, Asim* \\ Universitas Negeri Malang, Jl. Semarang No. 5 Malang, Jawa Timur, Indonesia \\ *Penulis korespondens, Surel: asim.fik@um.ac.id
}

Paper received: 3-2-2022; revised: 22-2-2022; accepted: 27-2-2022

\begin{abstract}
The aim of the study was to determine the difference in the effect of the playing method and drill level II volleyball gandu on the learning skills for heading outcomes of level II volleyball scouting seventh grade students of SMP Negeri 1 Sugio. This study used an experimental method with a design two group, pretests, posttest, and design. The subjects 13 students in the play method learning group and 15 students in the method learning group drill. Based on the one-way analysis of variance with a significance of $a=0.05$, the following results can be obtained: (1) The play method group obtained a significant $0.003<0.05$, the average score for pretest the playing method was 65 and the posttest was 77.61, and the score posttest greater than the score pretest. (2) The method group drill obtained significant $0.001<0.05$, the average score for pretest the method drill was 68 and posttest 86.92 in the, and the score posttest was greater than the score pretest. (3) The results of hypothesis testing posttest and methods play drill a significant result obtained $0.007<0.05$, the average score of posttest method of playing at 77.61 and posttest method posttest 86.92 drill, scores posttest method drill greater than the score of posttest method played. It can be concluded that learning volleyball gandu level II using the method is drill more influential on the learning skills heading outcomes of level II scout volleyball than the playing method.
\end{abstract}

Key words: heading; play method; drill method; gandu volleyball level ii.

\begin{abstract}
Abstrak
Tujuan peneltian untuk mengetahui perbedaan pengaruh antara metode pembelajaran bermain dan drill bolavoli gandu level II terhadap hasil belajar keterampilan heading bolavoli gandu level II siswa kelas VII SMP Negeri 1 Sugio. Penelitian ini menggunakan metode eksperimen dengan rancangan two group, pretetest, posttest, dan design. Subjek berjumlah 26 siswa dengan 13 siswa kelompok pembelajaran metode bermain dan 15 siswa kelompok pembelajaran metode drill. Berdasarkan analisis varian satu arah dengan signifikansi $a=0,05$, dapat diperoleh hasil berikut: (1) Kelompok metode bermain memperoleh signifikan 0,003<0,05, rata-rata skor pretest metode bermain sebesar 65 dan posttest 77,61, dan skor posttest lebih besar daripada skor pretest. (2) Kelompok metode drill memperoleh signifikan 0,001<0,05 rata-rata skor pretest metode drill sebesar 68 dan posttest 86,92, dan skor posttest lebih besar daripada skor pretest. (3) Hasil uji hipotesis posttest metode bermain dan drill diperoleh hasil signifikan 0,007<0,05, rata-rata skor posttest metode bermain sebesar 77,61 dan posttest metode drill posttest 86,92, skor posttest metode drill lebih besar daripada skor posttest metode bermain. Dapat disimpulkan pembelajaran bolavoli gandu level II menggunakan metode drill lebih berpengaruh terhadap hasil belajar keterampilan heading bolavoli gandu level II daripada metode bermain.
\end{abstract}

Kata kunci: heading; metode bermain; metode drill; bolavoli gandu level ii.

\section{Pendahuluan}

Pendidikan merupakan bagian paling penting dalam kemajuan sebuah negara. Pendidikan di Indonesia merupakan sebuah alat untuk mencerdaskan generasi bangsa yang 
nantinya menjadi motor penggerak pembangunan bangsa. Menurut UU No. 20/2003 tentang sistem pendidikan nasional disebutkan bahwa "Pendidikan merupakan usaha sadar dan terencana suasana belajar dan proses pembelajaran agar peserta didik secara aktif mengembangkan potensi dirinya untuk memiliki kekuatan spiritual keagamaan, pengendalian diri, kepribadian, kecerdasan, akhlak mulia, serta keterampilan yang diperlukan dirinya, masyarakat, bangsa, dan negara"(Depdiknas, 2003).

Menurut UU No. 20/2003 tentang sistem pendidikan nasional disebutkan bahwa "tujuan pendidikan nasional adalah mengembangkan potensi peserta didik agar menjadi manusia yang beriman dan bertakwa kepada Tuhan Yang Maha Esa, berakhlak mulia, sehat, berilmu, cakap, kreatif, mandiri, dan menjadi warga negara yang demokratis serta bertanggung jawab"(Depdiknas, 2003). Tujuan pendidikan nasional merupakan tujuan semua mata pelajaran yang ada di sekolah.

Di dalam pendidikan di Indonesia khususnya di sekolah banyak sekali hal yang perlu di perhatikan, baik dari dalam maupun dari luar sekolah. Setiap kegiatan yang ada di dalam sekolah perlu adanya partisipasi bukan hanya dari siswa saja, melainkan juga perlu adanya partisipasi dari seorang guru. Maka dari itu untuk mencapai pendidikan yang berkualitas butuh adanya cara untuk mendidik yang baik dan benar agar cita-cita pendidikan yang berkualitas dapat terwujud. Seorang guru sebagai fasilitator perkembangan peserta didik, agar perkembangan peserta didik dapat berjalan dengan optimal sesuai dengan kemampuan dan potensinya, guru harus mampu memperhatikan kurikulum pendidikan yang berlaku. Kurikulum dirancang sebagai pijakan guru dalam memberikan pendidikan kepada peserta didik, sehingga nantinya cita-cita pendidikan yang berkualitas dapat terwujud.

Menurut (Subandijah, 1994:48) "kurikulum adalah alat yang digunakan untuk mencapai tujuan pendidikan yang dinamis" kurikulum harus mampu menyesuaikan perkembangan zaman, semakin maju suatu zaman kurikulum harus disesuaikan dengan kebutuhan pendidikan. Pengembangan kurikulum harusnya dapat mengakomodasi kebutuhan dan bakat peserta didik sehingga tujuan pendidikan Indonesia dapat tercapai. Karena pada dasarnya siswa adalah objek utama atau peran utama dalam setiap kegiatan yang ada di sekolah. Sehingga perlu adanya arahan dan dukungan oleh guru agar dapat terwujud pendidikan yang berkualitas.

\section{Metode}

Rencana atau strategi yang digunakan oleh peneliti dalam mengumpulkan, menyajikan, dan menganalisis data atau informasi yaitu menggunakan metode eksperimental semu dengan perluasan rancangan pretest dan posttest dengan pemilihan kelompok yang diacak. Subjek penelitian ini adalah siswa kelas VII SMPN 1 Sugio yang berjumlah 26 siswa dengan 13 siswa kelompok pembelajaran metode bermain dan 15 siswa kelompok pembelajaran metode $d r i l l$.

\section{Hasil dan Pembahasan}

Berdasarkan analisis varian satu arah dengan signifikansi $a=0,05$, dapat diperoleh hasil berikut: (1) Kelompok metode bermain memperoleh signifikan 0,003<0,05, dengan rata-rata skor pretest metode pembelajaran bermain sebesar 65 dan posttest 77,61, dan dengan demikian skor posttest lebih besar daripada skor pretest. (2) Kelompok metode drill memperoleh hasil signifikan $0,001<0,05$ dengan rata-rata skor pretest metode pembelajaran drill sebesar 68 dan posttest 86,92, dan dengan demikian skor posttest lebih besar daripada skor pretest. (3) Hasil uji hipotesis data posttest metode bermain dan metode drill. 


\section{Tabel 1. Hasil Analisis Varian Satu Arah Posttest dan Posttest Metode Pembelajaran Bermain dan Metode Pembelajaran Drill Terhadap Hasil Belajar Keterampilan Heading Bolavoli Gandu Level II}

\begin{tabular}{llllll}
\hline Metode Latihan Bermain & Sum of Square & Df & Mean Square & F & Sig \\
\hline Between Groups & 563,115 & 1 & 563,115 & 8,833 & 0,007 \\
Within Groups & 1530,000 & 24 & 63,750 & & \\
Total & 2093,115 & 25 & & & \\
\hline
\end{tabular}

Berdasarkan analisis varian satu arah pada tabel 4.14, dapat diperoleh hasil signifikan 0,007<0,05 maka Ho ditolak dan Ha diterima. Sehingga terdapat perbedaan pengaruh rata-rata skor hasil belajar keterampilan heading bolavoli gandu level II sebelum dan sesudah diberikan perlakuan dengan menggunakan metode pembelajaran drill. Rata-rata skor posttest metode pembelajaran bermain sebesar 77,61 dan posttest metode pembelajaran drill posttest 86,92, dengan demikian skor posttest metode pembelajaran drill lebih besar daripada skor posttest metode pembelajaran bermain. Sehingga dapat disimpulkan pemebelajaran bolavoli gandu level II menggunakan metode pembelajaran drill lebih berpengaruh terhadap hasil belajar keterampilan heading bolavoli gandu level II pada siswa daripada metode pembelajaran bermain.

Berdasarkan hasil dari hipotesis penelitian bahwa terdapat pengaruh yang signifikan pada metode pembelajaran bermain terhadap hasil belajar heading bolavoli gandu level II. Berdasarkan hasil uji hipotesis penelitian dengan menggunakan anova satu jalur pada kelompok metode pembelajaran bermain yaitu taraf signifikansi $0,003<0,05$ maka Ho ditolak dan Ha diterima, sehingga menyatakan bahwa terdapat perbedaan pengaruh rata-rata skor hasil belajar keterampilan heading bolavoli gandu level II sebelum dan sesudah diberikan perlakuan menggunakan metode bermain. Rata-rata skor pretest metode pembelajaran bermain sebesar 65 dan posttest 77,61, dan dengan demikian skor posttest lebih besar daripada skor pretest. Sehingga dapat disimpulkan pemebelajaran bolavoli gandu level II dengan menggunakan metode pembelajaran bermain berpengaruh terhadap hasil belajar keterampilan heading bolavoli gandu level II pada siswa.

Berdasarkan hasil dari hipotesis penelitian bahwa terdapat pengaruh yang signifikan pada metode pembelajaran drill terhadap hasil belajar heading bolavoli gandu level II. Berdasarkan hasil uji hipotesis penelitian dengan menggunakan anova satu jalur pada kelompok metode pembelajaran drill yaitu taraf signifikansi 0,001<0,05 maka Ho ditolak dan Ha diterima. Sehingga terdapat perbedaan pengaruh rata-rata skor hasil belajar keterampilan heading bolavoli gandu level II sebelum dan sesudah diberikan perlakuan dengan menggunakan metode pembelajaran drill. Rata-rata skor pretest metode pembelajaran drill sebesar 68 dan posttest 86,92, dan dengan demikian skor posttest lebih besar daripada skor pretest. Sehingga dapat disimpulkan pemebelajaran bolavoli gandu level II menggunakan metode pembelajaran drill berpengaruh terhadap hasil belajar keterampilan heading bolavoli gandu level II pada siswa.

Berdasarkan hasil dari hipotesis penelitian bahwa terdapat perbandingan pengaruh yang signifikan pada metode pembelajaran bermain dan metode pembelajaran drill terhadap hasil belajar heading bolavoli gandu level II. Hipotesis tersebut terbukti berdasarkan analisis varian satu arah dapat diperoleh hasil signifikan 0,007<0,05 maka Ho ditolak dan Ha diterima. Sehingga terdapat perbedaan pengaruh rata-rata skor hasil belajar keterampilan heading 
bolavoli gandu level II sebelum dan sesudah diberikan perlakuan dengan menggunakan metode pembelajaran drill. Rata-rata skor posttest metode pembelajaran bermain sebesar 77,61 dan posttest metode pembelajaran drill posttest 86,92, dengan demikian skor posttest metode pembelajaran drill lebih besar daripada skor posttest metode pembelajaran bermain. Sehingga dapat disimpulkan pemebelajaran bolavoli gandu level II menggunakan metode pembelajaran drill lebih berpengaruh terhadap hasil belajar keterampilan heading bolavoli gandu level II pada siswa daripada metode pembelajaran bermain.

\section{Simpulan}

Berdasarkan penelitian yang telah dilakukan dapat disimpulkan bahwa: (1) Metode pembelajaran bermain bolavoli gandu level II berpengaruh terhadap hasil keterampilan heading bolavoli gandu level II siswa, dengan rata-rata nilai pretest sebesar 65 dan rata-rata nilai posttest sebesar 77,61. (2) Metode pembelajaran drill bolavoli gandu level II berpengaruh terhadap hasil keterampilan heading bolavoli gandu level II siswa, dengan rata-rata nilai pretest sebesar 68 dan rata-rata nilai posttest sebesar 86,92. (3) Metode pembelajaran drill bolavoli gandu level II dapat memberikan pengaruh yang lebih terhadap hasil belajar keterampilan heading bolavoli gandu level II siswa kelas VII SMP Negeri 1 Sugio dibandingkan dengan metode pembelajaran bermain.

\section{Daftar Rujukan}

Abdullah, B., Shafie, N. A., Yusof, A., Shamsudin, S., \& Salehhodin, S. N. (2018). Growth Motor Development Levels of Young Children in Cricket, Volleyball and Athletics. International Journal of Academic Research in Business and Social Sciences. https://doi.org/10.6007/ijarbss/v7-i14/3666

Anggreani, Y., Supriatna, E., \& Yunitaningrum, W. (2019). Metode Bermain Terhadap Hasil Belajar Teknik Dasar Passing Bawah Bola Voli Di Smp. Jurnal Pendidikan Dan Pembelajaran Khatulistiwa 3.9.

Aprianova, F. (2016). Metode Drill Untuk Meningkatkan Teknik Dasar Menggiring Bola ( Dribbling ) Dalam Permainan Sepakbola Pada Siswa Sekolah Sepakbola Putra Zodiac Kabupaten Bojonegoro Usia 13-15 Tahun. Jurnal Kepelatihan Olahraga.

Asim, A. 2001. Bola Voli Gandu. Malang: Wineka Media.

Astuti, Y. (2017). Pengaruh Metode Drill dan Metode Bermain Terhadap Keterampilan Bermain Bola Voli Mini (Studi Eksperimen Pada Siswa SD Negeri 14 Kampung Jambak Kecamatan Koto Tangah Kota Padang). Al Ibtida: Jurnal Pendidikan Guru MI. https://doi.org/10.24235/al.ibtida.snj.v4i1.1276

Budiwanto, S. (2017). Metode Statistika. Malang: Universitas Negeri Malang.

Burhaein, E. (2017). Aktivitas Fisik Olahraga untuk Pertumbuhan dan Perkembangan Siswa SD. Indonesian Journal of Primary Education. https://doi.org/10.17509/ijpe.v1i1.7497

Chagas, D. V., Ozmun, J., \& Batista, L. A. (2017). The relationships between gross motor coordination and sportspecific skills in adolescent non-Athletes. Human Movement. https://doi.org/10.1515/humo-20170037

Roji, E. (2017). Pendidikan Jasmani, Olahraga dan Kesehatan. Jakarta: Kemendikbud.

Jakiwa, J., \& Suppiah, P. K. (2020). The differences between gross motor performance amongst children according to ethnic and age chronology. Malaysian Journal of Movement, Health \& Exercise 9.1.

Juniati, E. (2017). Peningkatkan Hasil Belajar Matematika Melalui Metode Drill Dan Diskusi Kelompok Pada Siswa Kelas VI SD. Scholaria: Jurnal Pendidikan Dan Kebudayaan. https://doi.org/10.24246/j.scholaria.2017.v7.i3.p283-291

Khotimah, N. (2020). Penerapan Metode Drill Untuk Meningkatkan Keterampilan Passing Atas Bola Voli Siswa SMPN 4 Tapung Hilir. Ournal of Education and Teaching 1.1.

Ihsan, I. (2019). Pengaruh Metode Bermain Dan Metode Latihan Terhadap Hasil Belajar Pendidikan Jasmani Olahraga Dan Kesehatan (Penjasorkes). Jurnal Penjakora - Ejournal.Undiksha.Ac.Id. 
Nugraha, L. (2019). Pengaruh Metode Pembelajaran Drilling Jarak Pendek Terhadap Hasil Belajar Renang Gaya Dada. Jurnalmahasiswa.Unesa.Ac.Id.

Kiranida, K. (2019). Memaksimalkan Perkembangan Motorik Siswa Sekolah Dasar Melalui Pelajaran Penjaskes. Tunas Bangsa Journal, 2019 - Ejournal.Bbg.Ac.Id.

Rodiansyah R. (2018). Pengaruh Metode Bermain Terhadap Gerak Dasar Dribbling Dalam Permainan Sepakbola. Ejournal.Upi.Edu.

Sepriadi, S. (2017). Kontribusi Status Gizi Dan Kemampuan Motorik Terhadap Kesegaran Jasmani Siswa Sekolah Dasar. Jurnal Keolahragaan. https://doi.org/10.21831/jk.v5i2.15147

Setyo, U. A. I., \& Winarno, M. E. (2020). Upaya Meningkatkan Hasil Belajar Tolak Peluru Gaya Ortodok Melalui Metode Bermain di SMP Negeri 1 Durenan. Sport Science and Health, 2(2), 99-104.

Subandijah, S. 1994. Pengembangan dan Inovasi Kurikulum. Jakarta: Raja Grafindo Persada.

Wallhead, T. L., Garn, A. C., \& Vidoni, C. (2014). Effect of a sport education program on motivation for physical education and leisure-time physical activity. Research quarterly for exercise and sport, 85(4), 478-487.

Winarno, M. E. (2014). Teknik Dasar Dan Taktik Bermain Bola Voli. Universitas Negeri Malang.

Yahya, A. A., \& Sufitriono, S. (2020). Pembelajaran Metode Drill Untuk Meningkatkan Hasil Belajar Passing Bawah Pada Permainan Bolavoli Siswa SMPN 2 Mare Kabupaten Bone. Jendela Olahraga. https://doi.org/10.26877/jo.v5i1.4179 